\title{
School University Consortium to Enhance General Certificate Student's Prospective and Academic Performance in Palestine
}

\author{
Derar Eleyan $^{1}$, Muath Sabha ${ }^{2}$, Amna Eleyan ${ }^{3} \&$ Jaafar Abu Saa ${ }^{4}$ \\ ${ }^{1}$ Applied Computing Department, Palestine Technical University Kadoorie, Tulkarem P.O. Box 7, Palestine \\ ${ }^{2}$ Faculty of Engineering, Arab American University, Jenin, Palestine \\ ${ }^{3}$ School of Computing and Mathematics, Manchester Metropolitan University, Manchester M15 6BH, UK \\ ${ }^{4}$ Faculty of Arts and Educational Sciences, Palestine Technical University Kadoorie, Tulkarem P.O. Box 7, \\ Palestine \\ Correspondence: Jaafar Abu Saa, Faculty of Arts and Educational Sciences, Palestine Technical University \\ Kadoorie, Tulkarem P.O. Box 7, Palestine.
}

Received: September 16, 2020

doi:10.5539/mas.v15n2p1
Accepted: February 19, 2021

Online Published: February 25, 2021

URL: https://doi.org/10.5539/mas.v15n2p1

\begin{abstract}
This paper introduces a conceptual platform for bringing students and teachers together in a social media consortium. The results extracted from the questionnaire used in this paper exhibits that the majority of the students support and are eager to see this idea live and willing to play an active role and show full commitment. This consortium encompasses students and teachers from both school and university. This platform prepares the students, fosters and enables them to a smooth transition from school to university, as well as improving the students' communication skills and academic performance by using mentoring, tutoring and coaching techniques. As a case study of social media, Facebook was used as a communication and interactive tool amongst group members. The theme behind this platform is to construct academic group from final year school students with first year university students to exchange experience and transfer knowledge. This group has school teachers as well as university teachers. Each group has a mentor, coach and tutor. Each of them will play a specific role throughout the group, which will be highlighted in this paper. The outcomes were useful and interesting for students, their parents and teachers involved. It was a great experiment and recommended to widen it to involve more students and teachers.
\end{abstract}

Keywords: social media, Facebook, mentoring, coaching, tutoring, academic quality, general certificate

\section{Introduction}

Student-centered learning strategies, especially in the higher education sector, have had more emphasis over the last twenty years. This emphasis is accompanied by more considerations for utilizing technology and exploiting its ubiquity and the role it could play to consolidate and support effective learning (Roblyer et al., 2010). The teacher is no longer the only source of information and his/her role should be evolved from teaching into monitoring and supervising in the teaching and learning process as a whole. The availability of technology now-a-days, and social media as a special case, should ease the teachers' duties and aid them to play different roles as tutors, mentors and coaches. This paper explores the acceptance and readiness of both students and teachers to use social media as a platform for interactive learning means and an effective communication tool to overcome and bridge the gap between school and university life. A questionnaire has been prepared and disseminated amongst female and male students from a final year of a school who are potential university students in addition to their teachers. The questionnaire shows the availability of the technology and Internet access among the surveyed students and teachers, which makes life easy to use social media, and as a case study Facebook, as a communication tool. A group in face book has been created and involved of students from both the university and school with their teachers started utilizing social media and evaluating the efficiency and effectiveness of the process by evaluating the feedback from participants.

\section{Research Rationale}

The rationale behind conducting this study is to explore the requirements, preparation and readiness of students and teachers using social media as a communication tool to improve the school student's communication and 
study skills and prepare them for university life. An addition expected result is also how to help the school students utilize their full potential and creativity to maximize their academic achievements by exposing them to experienced students and staff to help them secure the desired place at the university. This will improve their future perspectives and help them select the appropriate subject to study. By improving their awareness of future life and preparing them for experiencing a new environment totally different than the school environment which could lead to improvements in their behavior and maximize retention and graduation rate. The proposed platform will enhance student-teacher engagement in an informal environment, which will eliminate some barriers, build trust in the relationship, increase the students' confidence, and improve different required skills.

\section{Literature Review}

The paper subject has not been tackled directly by researchers, while the social media occupied a huge area in the research fields of school and university education. In this section, the researchers mentioned some of the most related and newest papers.

Mazzoni and Iannoni (2013) defined the social capital in a different way based on the student position. According to their study, social networks may facilitate subsequent insertion into the university context. The study referred to Italian culture which may be similar to most European countries but not the Middle East.

Using different means of social media could offer a new paradigm to enhance and foster the learning experience. Greenhow and Gleason (2012) anticipate the use of Twitter as a new literacy practice to enhance Learning in higher education which could improve the students' engagement and achieve better interaction between students and their teachers and lecturers. Fusch (2011) supports the use of such social media to promote students' social presence, create interactive teaching and learning environment and consolidate collaborative study amongst students.

Dunn (2012), Kuh (2005) also suggested to augment the use of technology in teaching and learning and urge more emphasis and exploitation of technology in the learning environment and this requires an extended degree of technological engagement. Frozzi and Mezzoni (2011) showed the social networks in supporting the emerging adults in maintaining and developing their social capital.

Zepke and Leach (2010) show that the integration of technology into the learning and teaching process is quite important as the line between socialization and online learning becomes blurred. They also suggest that students' dispositions and motivation will positively affect their engagement in the interactive learning process.

While Elbadawy and Hashim (2015), on the other hand, stated that there is no relation between academic achievement and the use of social networks. Their results were derived from a study they did over a big number of university students.

The School of Education at Glasgow University has conducted a study on the usage of social media in the learning environment (Glasgow University, 2013). The study focuses on how many of the students currently use social media, what kind of social media they use, what the purpose of using it is, and do they believe that if they use it as a learning tool it will enhance their learning experience. An online survey was used and disseminated amongst the college students. The results of the survey are shown in Figures 1 and 2.

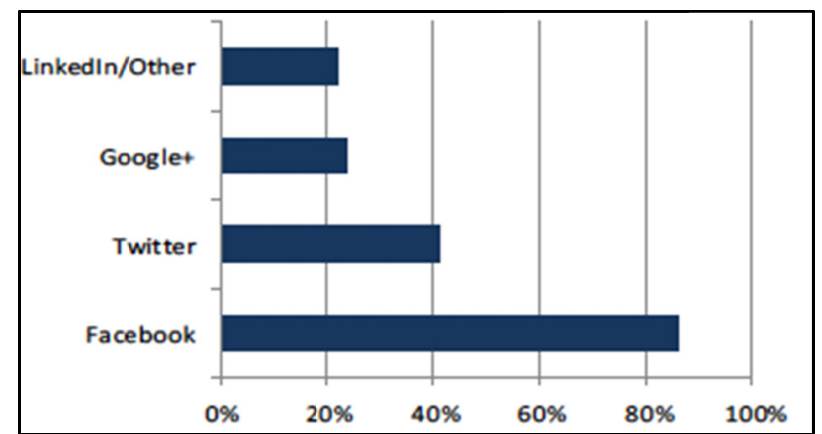

Figure 1. Social media types used by the students (Glasgow University, 2013) 


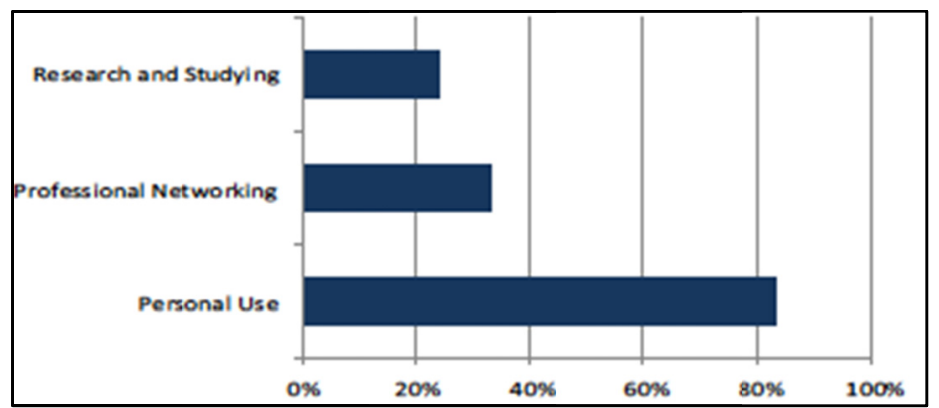

Figure 2. The purpose of using social media (Glasgow University, 2013)

The following are some of the valuable comments, students have provided throughout the study.

"It is a convenient way to interact with specific people and get feedback quickly, and also a more attractive approach which is welcomed by young people who live in the age of IT"

"Yes, social media is a valuable tool to use within higher education. It can enhance learning as students can be connected to tutors, peers, etc. 24/7. The hierarchies are broken down and everyone can share ideas."

"No, I don't think that social media is a useful way in which to learn. It provides only a superficial contact with peers/staff and can detract from essential skills which should be developed in higher education such as formal academic writing, verbal communication, self-awareness and reflection on the learning experience".

As there are invaluable opportunities offered by social media, there are many challenges as privacy and high chances of miscommunication and misunderstanding because of the lack of face-to-face contact. These concerns and challenges need to be considered when planning for group activities; otherwise it may increase difficulty and cause negative impacts (Zaidieh, 2012). This problem can be overcome by using the Facebook group as a supplementary tool to the traditional methods of face-to-face conversation but not as an alternative. The privacy issues will be handled by offering individual tutoring in the form of face-to-face meetings.

\section{Benefits of Using Social Media as a Learning Tool}

A study conducted by Glasgow University highlighted some important benefits of using social media as a learning tool in the higher education environment (Glasgow University, 2013):

- The student becomes more motivated and engaged with the course material;

- Promote and enhance student-to-student collaboration as well as student lecturer/teacher interaction;

- Accelerated data and information sharing and eliminate barriers to self-expression and contribution;

- $\quad$ Removes barriers to self-expression and contribution;

- $\quad$ Provides students with $21^{\text {st }}$ Century skills which could improve their employability and increase levels of satisfaction

At the other hand, (Heffner, 2016) conducted a study at Rowan University to see how social media use by undergraduate students affects their academics as well as their social life in college. The involved participants where 116 undergraduate students who use different social media such as Twitter, Facebook, Instagram, and SnapChat. The study found that social media use by undergraduate students does not positively affect their academics and social life in college, denying the previous results.

In our case, the last claim of (Heffner, 2016) does not affect our study, and that is because the social media is an environment that brings students together to explore their expectations of their future world, and to help them know the real environment they are going to live at the university.

\section{Mentoring, Tutoring and Coaching}

Mentoring, tutoring and coaching are processes used in academia as well as in business to enhance the individual's full potential by offering ongoing support and development opportunities (Clutterbuck, 2004). Many authors define mentoring as "offering help and support to learners through their transition from one stage of professional development to another, to help the others to achieve their goals" (Wallace and Gravells, 2005). Indeed social media can be a suitable environment for encouraging informal discussion openly and confidently. 
While tutoring is helping audience to prepare for the exams and provides them with academic skills and subject knowledge. The coach is more experienced than the tutor and has focused expertise (Megginson and Clutterbuck, 2005).

The university fresher's year students face various problems as they are exposed to a new and totally different environment. These problems can affect their academic performance and sometimes take them a lot of time to settle down and integrate with university life. Using social media as a tool of tutoring and mentoring could help them overcome these difficulties and smoothen their integration in the university life. This tool should be used in the final year of school life to arm them with the necessary skills of planning for future study.

A school or university teacher could play the role of mentoring, as he/she is an experienced person of relative authority, specific skills and has a valued perspective by the learner. The institute of management highlighted some essential mentoring skills (People Management, 1999). The mentor should be an active listening, reading, concentrate on what the mentee is saying, showing full understanding and responding positively to students concerns and queries. Susan Wallace and Jonathan Gravells suggest some ways to follow to perform active listening (Wallace and Gravells, 2006).

As long as the mentor should have some skills to perform well in the mentoring process, the mentee should have correspondent skills to play the effective role as a mentee and be well prepared to communicate and perform to reap the benefits from mentoring. In the mentoring process, much depends on the skills and attributes of the mentee. The mentee can learn to become a skilled mentee.

Sarah Hartley in her mentoring and coaching skills development guidance pack (Hartley, 2006) suggests that the mentoring process is a three-staged process of exploration, new understanding and action which makes the mentoring process useful to use within mentoring conversations.

\section{Exploration}

Exploration stage is where the mentor uses questions, listening, and negotiation besides the following principles to facilitate the mentoring process:

- Take the lead to open the discussion and pay attention to the relationship.

- Clarify aims, objectives and discuss ground rules and support and counsel the mentee.

\section{New Understanding}

In this stage the mentor supports, counsels, offers feedback, coaches and demonstrates skills besides using listening and challenging, using both open and closed questions and giving information and advice to help the mentee identify learning and development needs.

\section{Action}

The mentor may examine options and consequences, negotiate and develop the action plan by encouraging new ideas and creativity, helping in decisions and problem solving, and agree the proposed action plans and monitor and review its progress.

However, the mentoring process rarely moves in a straight line from stage one to stage three. More, often, in use, the conversation moves about between all of the stages. The mentor has a temptation and the desire to get the action as quickly as possible but often the quality and the commitment to the action are dependent on the quality of stage one and two.

\section{Methodology}

We have reviewed some relevant literature and studies to explore the feasibility of using social media as a learning tool as well as a process of tutoring, mentoring and coaching. We also prepared two questionnaires to understand the readiness and willingness of both students and teachers of adopting and using the social media in the teaching and learning process; one questionnaire was designed for the students and the other one was for teachers. These two questionnaires are dissimilated to two different schools; girls and boys. The total sample was 157 students and 29 teachers. The data extracted from each questionnaire is analyzed according to the gender. Finally, the results are compared with their gender counterpart. Two tables are formulated to represent data separately.

\section{Platform Implementation}

As a result, from the early study, the following steps are proposed as a consolidated tool for teaching and learning. The recommended platform is to prepare and expose final year school students to university life. 


\section{1) Preparation}

Training sessions have been conducted to enable the teachers to play the role of mentoring, coaching and tutoring and how to use the technology, especially social media and other supplementary technology.

2) Conduct a physical meeting with the group of students involved in the study with their teachers from the school and the university,

\section{3) Create a Facebook Group}

A Facebook group has been created Each and contains ten final year school students with a balanced gender ratio (male and female) from two different schools and three university students and two staff members, one from the school and the other from a university.

\section{4) Assign Roles to Each Staff Member}

The schoolteacher is the group tutor to help the students with the daily school duties and involve the subject matter expert where required. The university instructor plays the role of mentor and coach. In addition to that, he/she supervises the whole process to ensure positive achievements.

\section{5) Posting Queries, Concerns And Problems}

The students started posting their queries, concerns and problems in their learning and creating an interactive environment where their peers and schoolteachers tried to answer the queries, propose solutions and the university teacher contributed where possible and monitored the responses and validated the answers.

The tutor encouraged each member of the group especially the students to find creative ideas and subjects and raise them for discussion.

\section{6) ENCOURAGE STUDENTS CREATIVITY}

Encourage each member of group especially the students to look for creative ideas and subjects and bring them for discussion. This could be in monthly basis or open to anyone who has an idea for discussion.

\section{7) Posting Supplements and Teaching Materials}

The teachers or university students and different group members posted relevant materials including websites for the students to look at for assisting them in finding the answers and consolidated their learning progress.

\section{8) Parents Involvement}

Parents are invited from time to time in the interactive environment and exposed their concerns, gave advice and monitoring and witness the performance and the behavior of their children and scan the comments and queries on the platform.

\section{9) Conducting Periodic Meetings}

University instructor conducted periodic meetings with the whole group three times in the semester. One meeting conducted in the school environment which was a good opportunity for university teacher to meet school staff and deliver an inspirational lecture to students; the other meeting was in the university environment and a third one was face-to-face.

\section{Results and Discussion}

The questionnaire used in this research aimed to explore the potential of teachers of both genders and their readiness and willingness to use social media for academic purposes. Table 1 shows the findings of the teacher questionnaire. It shows that 9 out of 11 male teachers expressed their needs and interests to improve their communication and study skills while all of the female teachers are interested in improving their communication and study skills to enrich their subject expertise and maximize their performance. All teachers (males and females) believe that utilizing social media, Facebook as a case, could improve and foster their personality, team-working skills and offer them the opportunity to get experience, supervision and help from other peers. All of the surveyed teachers are using the internet between two to four hours a day. Most of them are using social media for socialization purposes, which represents a good potential to utilize it for academic purposes. 
Table 1. Teacher's questionnaire findings

\begin{tabular}{llcccc}
\hline & & \multicolumn{2}{c}{ Male (11) } & \multicolumn{2}{c}{ Female (18) } \\
\cline { 3 - 5 } Improvement Skills & & Yes & No & Yes & No \\
\cline { 2 - 5 } (needed) & Communication Skills & 9 & 2 & 18 & 0 \\
& Study Skills & 7 & 4 & 16 & 2 \\
Facebook Utilization & Foster Personal Skills & 8 & 3 & 17 & 1 \\
(Prospective) & Team Working & 11 & 0 & 16 & 2 \\
Internet Access & Get Experience, Supervision, Help & 11 & 0 & 16 & 2 \\
(daily) 2 hours or less & Less 2Hours & & 4 & & 3 \\
Facebook Usage & Sore 2 Hours & & 5 & & 12 \\
& Socialization & & 7 & & 11 \\
\hline
\end{tabular}

Table 2 below shows the students potential, readiness and willingness to use social media in their learning process and to prepare them for university life. It shows that $100 \%$ of both female and male students are looking to improve their communication and study skills to improve their performance, which enables them to study their own choice at the university and to attain better future. $80 \%$ of male students are not fully aware of university life, while $88 \%$ of female students share the same feelings. Both students are using the internet around two hours a day on average surfing the Facebook for socialization purposes, which means they have the potential and are ready to use social media for academic purposes if they find someone to facilitate the process and lead them.

Table 2. Student's questionnaire findings

\begin{tabular}{llcccc}
\hline & & \multicolumn{2}{c}{ Male (77) } & \multicolumn{2}{c}{ Female (80) } \\
\cline { 3 - 6 } & & Yes & No & Yes & No \\
\cline { 2 - 5 } Improvement Skills (needed) & Communication Skills & 77 & 0 & 80 & 0 \\
& Study Skills & 73 & 4 & 73 & 7 \\
& Prospective of University Life & 62 & 15 & 70 & 8 \\
Facebook Utilization & Foster Personal Skills & 71 & 6 & 76 & 4 \\
(Prospective) & Team Working & 70 & 7 & 74 & 6 \\
& Get Experience, Supervision, Help & 73 & 4 & 77 & 3 \\
Internet Access* (daily basis) & Less 2Hours & & 17 & & 73 \\
& More 2 Hours & & 60 & & 7 \\
Facebook Usage & Socialization & & 74 & & 72 \\
\end{tabular}

* Internet Access: 99\% of the surveyed has internet access

There were a variety of benefits for the platform which have a positive impact on the students, teachers and parents, a survey had been conducted with the students and their parents and teachers involved and the results as follow:

- Students utilized their leisure and fully engaged in the study and find it very social and positively affected their academic performance as it motivated them to university. This was clear from a comparison of their performance before and after the experiment.

- Introduced school students to the evaluation and scoring process in university system.

- Introduced the school students to the way classes are registered and attended at the university.

- Introduced the newbies to the clubs, extracurricular activities and university scientific activities.

- Introduced school students to the university social life.

- Improved students' aspirations.

- Improved students' communication, study and research skills. 
- Parents were supportive and pleased for the outcome of the experiment and recommended to adopt this kind of education as a supplement tool to the traditional education.

- A feedback tool for both the school and the university to improve their performance and services.

- A platform to expose students to new emerging technologies.

- Enhanced ethical values such as privacy, copyright, honesty and trust.

- Knowledge transfer which helped to enable the current students to lead and share knowledge with other groups within the school and spread the new culture.

- Ensured the smooth integration of school students into university life where the involved students found more prepared for university life.

- Improved the students' behavior by understanding the real meaning of "undependability", "freedom", "responsibility" and "maturity" in their future life.

\section{Conclusion and Future Work}

The findings from the questionnaires show a similarity with findings from Glasgow University as the majority of the students surveyed are using social media for personal and social purposes with a difference that the target group at Glasgow University are university students while the target group in our study are final year school students. The results also highlighted the potential of both students and teachers and the necessity of implementing a platform to play a vital role in the teaching and learning process. The platform could be used in voluntary work. Another option for funding the system is the university and the school to pay extra money or part of the teachers load. Or, it could be used as a business tool with a suitable business model. The survey conducted with the students and their parents and teachers involved in the experiment found it very helpful and useful as supplement tool to enhance the teaching and learning process and contribute positively in the students integration in the university life.

Future work will be the utilization of the platform and the usage of social media in a large size and involve more students and teachers to utilize this technique to gain better outcomes and improves the student's skills and behavior and ultimately their academic performance, their awareness and readiness for university life.

\section{Acknowledgments}

It is my great pleasure to thank my university (Palestine Technical University-Kadoorie) for all the encouragement and support to achieve my research.

\section{References}

Clutterbuck, D. (2004). Everyone Needs a Mentor. London, Chartered Institute of Personnel and Development.

Conner, M., \& Pokora, J. (2007). Coaching \& Mentoring at Work: Developing Effective Practice. New York, McGraw Hill.

Connor, M., \& Pokora, J. (2007). Coaching and Mentoring at Work. London, Copyright Licensing Agency Ltd.

CUREE. (2005). Mentoring and Coaching National Framework. Retrieved from https://www.curee-paccts.com/dynamic/curee44.jsp

Dunn, L. (2012). Why it's Time to Start BOYD in your school on Edudemic. Retrieved from https://edudemic.com/2012/12/why-its-time-to-start-byod-in-your-school/

El-Badawy, T. A., \& Hashem, Y. (2015). The Impact of Social Media on the Academic Development of School Students. International Journal of Business Administration, 6(1). https://doi.org/10.5430/ijba.v6n1p46

Elemson, J. (Winter 2007). Mentoring in Further Education. InTuition: 4-5.

EMCC. (2007). Code of Ethics. Watford, European Mentoring \& Coaching Council. Retrieved from https://www.pbcoaching.com/about/ethics.php

Fletcher, S. (2000). Mentoring in Schools. London, Kogan Page Limited.

Frozzi, G., \& Mazzoni, E. (2011). On the importance of social network sites in the transitions which characterize emerging adulthood. ICST Transactions on e-Education and e-Learning, 11(7-9). https://doi.org/10.4108/icst.trans.eeel.2011.e4

Fusch, D. (2011). Social Media and Student Learning: Moving the needle on engagement in Academic Impressions. 
Dunn, L. (2013). Teaching in Higher Education: Can Social Media Enhance the Learning Experience? Retrieved from https://www.gla.ac.uk/media/media_276225_en.pdf

Greenhow, C., \& Gleason, B. (2012). Twitteracy: Tweeting as a New Literacy Practice. The Educational Forum, $76(4), 463-477$.

Hartley, S. (2006). Mentoring and Coaching Skills Development. Retrieved from https://www.tpct-tvcd.nhs.uk/what_we_do/Mentoring.php

Hay, J. (2007). Reflective Practice and Supervision for Coaches. New York, McGraw Hill.

Heffner, Tara. (2016). The effects of social media use in undergraduate students. Theses and Dissertations. Paper 1440 .

Holmes, E. (2002). The Newly Qualified Techer's Handbook. London, Kogan Page Limited. https://doi.org/10.4324/9780203820445

Kuh, G. D. (2005). Student Engagement in the First Year of College. In Challenging and Supporting the First-Year Student: A Handbook for Improving the First Year of College, edited by M. L. Upcraft, J. N. Gardner, and B. O. Barefoot, 86-107. San Francisco: Jossey-Bass.

Mazzoni, E., \& Iannone, M. (2013). From high school to university: Impact of social networking sites on social capital in the transitions of emerging adults. British Journal of Educational Technology, 45(2). https://doi.org/10.1111/bjet.12026

Megginson, D., \& Clutterbuck, D. (2005a). Making Coaching Work - Creating a coaching culture. London, CIPD.

Megginson, D., \& Clutterbuck, D. (2005b). Techniques for Coaching and Mentoring. Oxford, Elsevier Butterworth-Heinemann. https://doi.org/10.4324/9780080470580

Megginson, D., \& Clutterbuck, D. et al. (2006). Mentoring in Action. London, Kogan Page Limited.

Neil Thompson. (March 29, 2013). People Management. Publisher: Palgrave Macmillan.

Parsloe, E. (1992). Coaching, mentoring and assessing. Retrieved from https://www.niace.org.uk/information/briefing_sheets/38_ICT_Mentors.htm

Roblyer, M. D., McDaniel, M., Webb, M., Herman, J., \& Witty, J. (2010). Findings on Facebook in higher education: A comparison of college faculty and student uses and perceptions of social networking sites. The Internet and Higher Education, 13(3), 134-140. https://doi.org/10.1016/j.iheduc.2010.03.002

Stephens, P. (1995). Essential Mentoring Skills. Cheltenham, Stanley Thornes Ltd.

Tummons, J. (2007). Becoming a Professional Tutor in the Life Learning Sector. Exeter, Learning Matters Ltd.

Wallace, S., \& Gravells, J. (2006). Mentoring in Further Education: Meeting the National Occupational Standards. Exeter, Learning Matters Ltd.

Zaidieh, A. (2012). The Use of Social Networking in Education: Challenges and Opportunities. World of Computer Science and Information Technology Journal, 2(1), 18-21.

Zepke \& Leach. (2010). Improving Student Engagement: Ten Proposals for Action, Active Leaning. Higher Education, 11(3), 167-177. https://doi.org/10.1177/1469787410379680

Zeus, M., \& Skiffington, S. (2000). The Complete Guide to Coaching at Work. North Ryde, London, Mc Graw Hill.

\section{Copyrights}

Copyright for this article is retained by the author(s), with first publication rights granted to the journal.

This is an open-access article distributed under the terms and conditions of the Creative Commons Attribution license (http://creativecommons.org/licenses/by/4.0/). 